\author{
Research Article \\ www.ijrap.net
}

\title{
AYURVEDIC MANAGEMENT OF VATAHATA VARTMA (PTOSIS): A CASE STUDY
}

Ajoy Viswam ${ }^{1 *}$, Gururaj Anil Bhat ${ }^{2}$, Dheeraj BC ${ }^{3}$, Ashwini M J ${ }^{4}$

${ }^{1}$ PG Scholar, Department of Shalakya Tantra, SDM College of Ayurveda and Hospital, Hassan, Karnataka, India

${ }^{2}$ Assistant Professor, Department of Shalakya Tantra, SDM College of Ayurveda and Hospital, Hassan, Karnataka, India

${ }^{3}$ Associate Professor, Department of Shalakya Tantra, SDM College of Ayurveda and Hospital, Hassan, Karnataka, India

${ }^{4}$ Professor, Department of Shalakya Tantra, SDM College of Ayurveda and Hospital, Hassan, Karnataka, India

Received on: 15/07/17 Accepted on: 19/10/17

*Corresponding author
E-mail: ajoyviswam0312@gmail.com

DOI: 10.7897/2277-4343.086297

\begin{abstract}
Ptosis is a medical condition in which there occurs drooping or falling of upper eyelid. The condition gets worsened when there is exhaustion of the extra ocular muscles. This condition can be either uni ocular or binocular. When the condition is left untreated, it can lead to complications like astigmatism. Surgical intervention is the only line of treatment mentioned for ptosis as per the modern science. Ayurveda has given different treatment protocols for similar conditions. The present article discusses a case of uni ocular ptosis where a female patient of 36 years old visited the OPD with complaints of drooping of right upper eyelid since last 6 months. Initially the patient was managed by facial massage, sudation followed by instillation of nasal drops. Later eye massage was administered and then Shashtika Shalipinda sweda was administered for strengthening the extra ocular muscles. After one week of treatment there was an improvement in the grades of ptosis. This case study indicates how Ayurvedic treatment works in condition of ptosis. Ptosis is a pure Vătaja condition and the treatment principle mentioned below mitigates the vitiated vata in the eyes.
\end{abstract}

Keywords: Ptosis, Treatment protocol, surgical intervention

\section{INTRODUCTION}

Eyes are considered as the most important sense organ. They are protected by appendages of eye namely eyelids, eyebrows, conjunctiva, and lacrimal apparatus. Eyelids cover a major part of the eye where the upper eyelid covers about upper one by sixth of the cornea i.e. approximately $2 \mathrm{~mm}^{1}$. Ptosis is a medical condition where there occurs abnormal drooping of the upper eyelids. In ptosis patients the upper eyelid will cover more than $2 \mathrm{~mm}$ of cornea. It occurs due to dysfunction in the muscles that raise the eyelids and also due to nervous dysfunction. Superior rectus and levator palpebrae superioris are the muscles which show dysfunction in case of ptosis ${ }^{2}$. They are nourished by the oculomotor nerve. The condition can affect either one or both the eyelids. Its prevalence increases among the elderly as the muscles of eyelids begin to deteriorate. Ptosis can be congenital and acquired. Acquired ptosis is of four kinds.

- Neurogenic ptosis caused by innervation defects like third nerve palsy, Horner's syndrome, opthalmoplegic migraine and multiple sclerosis.

- Myogenic ptosis caused by acquired disorders of levator palpebral superioris or of the myoneural junction.

- Aponeurotic ptosis caused by the defects of levator aponeurosis in the presence of a normal functioning muscle.

- Mechanical ptosis caused by the excessive weight on the upper lid as in patients with lid tumors, multiple chalazia and lid edema ${ }^{3}$.

As per modern sciences, surgical intervention is the mode of treatment mentioned for patients with ptosis.

Ayurveda describes ptosis as Vatahatavartma. It is described as a vataja vartmagata roga. Acharyas have described it as asadhya vyadhi ${ }^{4}$. Prophylactic management is what is explained in classics. In the given case Vatahara line of treatment was adopted. Treatment principles began with oleation, sudation, nasal drop instillation whereby the vitiated vata was mitigated. Treatment ended with nourishing therapies which strengthened the extra ocular muscles thereby providing symptomatic relief in the patient.

\section{Consent}

All authors declare that written consent was obtained from the patients for publication of this research work.

\section{Ethical approval}

All authors hereby declare that all experiments have been examined and approved by the Institutional ethics committee and have therefore been performed in accordance with the ethical standards laid down in the 1964 Declaration of Helsinki.

\section{Case Report}

A 36 year old female patient, native of Sakaleshpura visited the OPD of Sri Dharmasthala Manjunatheshwara College of Ayurveda and hospital Hassan on $1^{\text {st }}$ February 2017. She presented with complaints of drooping of right upper eyelid since last 6 months. The complaints began with occasional watering from eyes, headache, and itching of both eyes one year back. Six months back she started to notice the drooping of her right eyelid. She had consulted in another hospital at Bengaluru for the same complaints and was diagnosed as myogenic ptosis and was posted for surgery. The patient opted for a second opinion at our Ayurveda Hospital. 
There was no history of diabetes mellitus and hypertension. Dietary history revealed more of dry food and irregular food habits which are a cause for vata vitiation. Her vitals were within normal limits. On general examination there was no pallor, edema, clubbed nails, cyanosis, icterus and lymphadenopathy. On systemic examination there was impairment in the central nervous system. The oculomotor nerve was affected which in turn lead to myogenic ptosis.

\section{On local examination}

Head posture: was kept in straight, erect position without any tilt.

Facial symmetry: both eyebrows were at the same level. There was slight deviation of the angle of mouth towards left.

Ocular posture: visual axes of two eyes were parallel to each other in primary position and were maintained in all position of gaze.

The visual acuity before treatments of both eyes were $6 / 6$, of right eye was $6 / 12$ before treatment which changed to $6 / 9$ after treatment. In the left eye 6/6 was observed before and after treatment.

The eyebrows were placed on either side of the face above eyelids, curved with their convexity upwards.

On eyelid examination, unilateral ptosis was present in the right eyelid, of degree $3 \mathrm{~mm}$. Marcus Gunn Jaw winking phenomenon was present. The levator function was observed as $5 \mathrm{~mm}$. The left eyelid covered $1 / 6^{\text {th }}$ of the cornea and lower lid touched the limbus.

The upper eyelashes of the affected and non-affected eye were directed forwards, upwards and backwards. Similarly the lower eye lashes were directed forwards downwards and backwards. There were no visible trichiasis and poliosis.

On examination of the lacrimal apparatus, skin was visible over the lacrimal sac redness was present in the right eye and swelling was absent.

On eyeball examination proptosis and enopthalmos was absent. The uni ocular and binocular movements were possible in both the eyes.

On conjunctival examination, congestion was present in the right eye. Chemosis, discolouration, follicles, papillae, pterigium and pingeculae were absent in both eyes.

The sclera was white in colour and covered by bulbar conjunctiva in both eyes.

On corneal examination, the size, shape, surface and transparency was normal.

On anterior chamber examination by normal torch light method, the iris showed presence of crypts, ridges and collaretes. The pupil was normal on examination in both the eyes with normal pupillary reflex.

The patient was admitted on $1^{\text {st }}$ of February 2017. Treatment plan for 7 days was:

1) Mukhabhyanga with Ashwagandha Balalakshaditaila ${ }^{5}$

2) Nasyakarma with Ksheerabala101 avarti (12 drops in each nostril ${ }^{6}$

3) Netrabhyanga with Ksheerabala101 avarti

4) Shashtikashali panda sweda (after nasya)

5) Seka withTriphala Kashaya ${ }^{7}$

6) Aschotana with Punarnava Arka (4 drops in eye) ${ }^{8}$

During the first day after Mukhabhyanga followed by Nasyakarma and Netra abhyanga, the patient felt lightness of head and a mild decrease in headache. Patient reported a feeling of coolness after Shashtikashali pinda sweda. On second day, the patient was in the same condition with not much of subjective complaints. By the third day of Nasya, the patient had complete relief from headache. She had relief from the burning sensation and foreign body sensation in both eyes. On the $7^{\text {th }}$ day of treatment the grade of ptosis was measured and it was $2 \mathrm{~mm}$ which showed the improvement in 7 days of treatment schedule. Patient was discharged with Ksheerabala (101) as Pratimarshanasya, Dhanwantharam taila (101) avarti 10 drops with milk orally before food. Patient was asked to come for review on $23^{\text {rd }}$ of February.

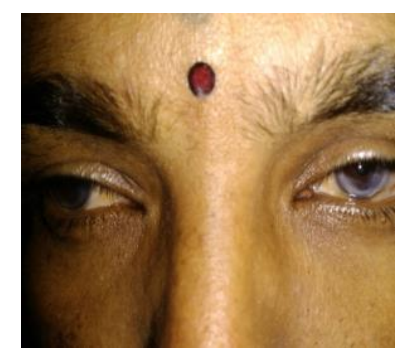

Figure 1: Before Treatment

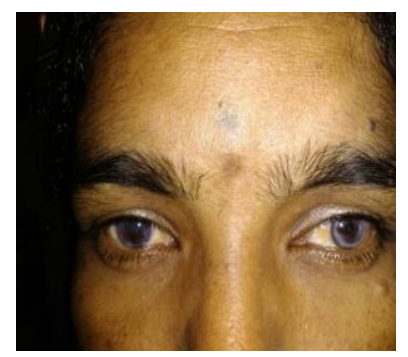

Figure 2: After Treatment

\section{DISCUSSION}

Ptosis is a condition where there is drooping of the upper eyelids. It worsens when the extra ocular muscles get exhausted. Ayurveda categorizes such a condition as asadhyavyadhi. It is named as vatahata vartma. Even though asadhya, a bhishak cannot leave a patient without addressing his present symptoms. Since it is a disease caused by vata, Vatahara line of treatment should be adopted. Vata should be mitigated by initial snehana followed by swedana and then shodhana. This is the principle applied here. Snehana was done with ashwagandha bala lakshadi taila. It not only mitigates vata but also strengthens the nervous supply. Mukhabhyanga is followed by nadi swedana which is a pre procedure before nasal instillation. This sudation helps in opening up the minute channels which are termed as Srotas as per ayurveda. This is followed by nasal instillation of ksheerabala (101) avarti. Ksheerabala is a preparation indicated in kevalavata Chikitsa. Avarti is the procedure where in the drugs are boiled again and the essence of drug is obtained to its maximum. 12 drops in a dosage which facilitates complete purification ${ }^{9}$. All the minute channels which were closed which in turn incapacitated the nourishment of nerves supplying the extra ocular muscles were stimulated by this procedure. It is a rule as per Ayurveda that once you do shodhana therapy you should give something as nourishment because a body which is purified absorbs in a better way than a body without purification. Similarly in this condition after shodhananasya, shashtikashalipindasweda was given on the eyelid. Pinda sweda is a kind of sudation. Shashtika shali panda sweda is indicated for nourishment of body. The same principle acted here. Later seka with triphala Kashaya was administered to bring down the itching and congestion of eye. Punarnava arka is a distillate preparation which was found effective in irritations due to dry 
eye syndrome. The patient had some foreign body sensation and dryness which reduced by the instillation of Punarnava Arka.

\section{CONCLUSION}

Ptosis is drooping or falling of the upper eyelid. Ptosis occurs due to dysfunction of the muscles that raise the eyelid or their nerve supply. It can affect one eye or both eyes and is more common in the elderly, as muscles in the eyelids may begin to deteriorate. The signs and symptoms of Ptosis can be compared with that of Vatahata vartma explained by Acharya Vagbhata in Ashtanga Hridaya. It is one among the Vartmagata rogas and the clinical feature is the appearance of partially closed eyelids due to Sandhinish cheshta (functional deterioration of the joint which facilitates the movement of eyelids). As the disease is vata dominant, Vatahara, Bhrumhana, Balya and Chakshushya line of treatment was adopted in this case and symptomatic improvement was observed.

\section{ACKNOWLEDGEMENT}

I am grateful to the patients and their bystanders for giving their time and support to carry out the treatment.

\section{REFERENCES}

1. Khurana.A.K. Comprehensive ophthalmology. $4^{\text {th }}$ edition New delhi; New age international, 2007; pp.27

2. Khurana.A.K. Comprehensive ophthalmology. $4^{\text {th }}$ edition. New delhi; New age international, 2007; pp.46

3. Khurana.A.K. Comprehensive ophthalmology. $4^{\text {th }}$ edition New delhi; New age international, 2007; pp.53

4. Arunadatta, Vaghbatta, Ashtanga Hridaya. Uttarasthanam Chapter $8 / 5$

5. Arunadatta. Vagbhatta Ashtanga Hridaya Uttarasthana Chapter 2/54-56

6. Arunadatta, Vagbhatta. Ashtanga Hridaya, Chikitsasthana; chapter 22/45-46

7. Dalhana, Nibanda sangraha. Sushruta Samhita, Uttaratantra $18 / 48$

8. Langhapathi Ravana. Arkaprakasha. Tripathi; Chaukambha krishnadas academy 2006 edition pp. 52

9. Arunadatta, Vagbhatta. Ashtanga Hridaya sutrasthana chapter $20 / 3$

\section{Cite this article as:}

Ajoy Viswam et al. Ayurvedic management of vatahata vartma (ptosis): A case study. Int. J. Res. Ayurveda Pharm. 2017;8(6):79-81 http://dx.doi.org/10.7897/2277-4343.086297

Disclaimer: IJRAP is solely owned by Moksha Publishing House - A non-profit publishing house, dedicated to publish quality research, while every effort has been taken to verify the accuracy of the content published in our Journal. IJRAP cannot accept any responsibility or liability for the site content and articles published. The views expressed in articles by our contributing authors are not necessarily those of IJRAP editor or editorial board members. 